\title{
Epidemiological Profile of Pediatric Vital Emergencies at Laquintinie Hospital of Douala, Cameroon
}

\author{
Penda Calixte Ida1,2,3* ${ }^{(}$, Endalè Mangamba Mireille-Laurent ${ }^{4,5}$, Samè Bebey Francine ${ }^{1,5}$, \\ Maledje Kamgang Kiliane Lariale ${ }^{2}$, Eposse Ekoubè Charlotte ${ }^{1,2}$, Eyoum Bilè Bertrand2, \\ Kedy Koum Danièle1,6*
}

\author{
${ }^{1}$ Department of Clinical Sciences, Faculty of Medicine and Pharmaceutical Sciences, University of Douala, Douala, Cameroon \\ ${ }^{2}$ Department of Pediatrics, Douala Laquintinie Hospital, Douala, Cameroon \\ ${ }^{3}$ Department of Pediatrics, Douala General Hospital, Douala, Cameroon \\ ${ }^{4}$ Department of Pediatrics, Faculty of Medical Sciences, University of Buea, Buea, Cameroon \\ ${ }^{5}$ Department of Medicine, Douala Laquintinie Hospital, Douala, Cameroon \\ ${ }^{6}$ Pediatrics Unit, District Hospital of Déido, Douala, Cameroon \\ Email: *Calix.penda@gmail.com, *dckedykoum@yahoo.fr
}

How to cite this paper: Ida, P.C., Mireille-Laurent, E.M., Francine, S.B., Lariale, M.K.K., Charlotte, E.E., Bertrand, E.B. and Danièle, K.K. (2021) Epidemiological Profile of Pediatric Vital Emergencies at Laquintinie Hospital of Douala, Cameroon. Open Journal of Pediatrics, 11, 148-160. https://doi.org/10.4236/ojped.2021.111014

Received: February 26, 2021

Accepted: March 28, 2021

Published: March 31, 2021

Copyright $\odot 2021$ by author(s) and Scientific Research Publishing Inc. This work is licensed under the Creative Commons Attribution International License (CC BY 4.0).

http://creativecommons.org/licenses/by/4.0/

(c) (i) Open Access

\begin{abstract}
Introduction: In the absence of health coverage in resource limited-settings, life-saving pediatric emergencies remain a challenge. The objective of our study was to describe the epidemiological profile of life-threatening pediatric emergencies at Laquintinie Hospital in Douala (HLD). Methods: A cross-sectional study was carried out for a period of 3 months, from March to May 2017 in the pediatric emergency unit of HLD enrolling all children presenting a lifethreatening emergency on admission. Local emergency kits and an internal deferred cost recovery voucher or "green voucher" were used to facilitate access to care for children on admission. The socio-demographic, clinical, therapeutic and evolutionary characteristics were collected and analyzed using SPSS software version 20.0. Results: A total of 135 children were enrolled and the sex ratio was 1.54 . The mean age was 3.8 years \pm 4.05 and $80.7 \%$ of the children were under 5 years old. The majority of children (82.9\%) admitted to the emergency room came from peripheral health structures. The hospital prevalence of life-saving emergencies was $42.4 \%$. The mean time to consultation after the onset of symptoms was 5.9 days and $66.0 \%$ of admissions were made during the 3 p.m. to 8 a.m. time slot. More than $4 / 5$ of emergencies were neurological, respiratory and cardio-circulatory emergencies representing $35.6 \%$ and $18.5 \%$ respectively. Severe malaria accounted $31.9 \%$ of the etiologies, bronchopneumopathies and meningo-encephalitis were involved in $18.5 \%$ and $17.8 \%$ of cases respectively. Patients were managed within 30 minutes of ad-
\end{abstract}


mission in $75.6 \%$ of cases and $52.6 \%$ of them received a "green voucher". The average length of stay in the emergency room was 6 days. The death rate from life-threatening emergencies was $17.8 \%$ and represented $61.5 \%$ of total deaths recorded in pediatric emergencies. Conclusion: The profile of lifethreatening emergencies at the HLD was that of a child under 5 years old, coming from a peripheral health facility and presenting a neurological emergency.

\section{Keywords}

Vital Emergencies, Pediatrics, Douala Laquintinie Hospital, Cameroon

\section{Introduction}

In 2017, $50 \%$ of deaths of children under 5 years old worldwide occurred in subSaharan Africa, one in 13 children died before their fifth birthday [1]. Most of these deaths are due to preventable causes such as birth complications, pneumonia, diarrhea, neonatal sepsis and malaria. After the age of 5 years more deaths occur as a result of trauma, mainly caused by drowning and road accidents, children residing in sub-Saharan Africa were 15 times more likely to die than European children [1]. In 2018 in Cameroon, the infant mortality quotient was estimated at 48/1000 [2]. Although emergency medicine is poorly developed in resource-limited setting, visits to emergency departments have increased dramatically in recent years. The Center of Disease Control (CDC) reports an increase of over 35\% in emergency room visits in the USA in 2009 compared to 1996 [3]. In France in 2014, the use of emergency services in general would have doubled in 10 years [4]. In previous studies in Africa, infectious pathologies were often found in children under 5 years of age consulting at pediatric emergencies, malaria being the most common etiology. Pediatric emergency unit mortality rates ranged from $8 \%$ to $17.3 \%$ [5] [6] [7]. Few studies have been conducted on critical pediatric emergencies in a resource-limited setting, especially in Cameroon where no studies were available. To improve mortality due to critical pediatric emergencies, the objective of this work was to describe the epidemiological profile of children with life-threatening emergencies on admission and their evolution.

\section{Methods}

\subsection{Study Type and Location}

This is a cross-sectional study carried out by simple consecutive sampling of children aged 1 to 15 years admitted at the pediatric emergency department of the Laquintinie Hospital Douala (LHD) from March to May 2017 (3 months). All children presenting a life-threatening emergency (neurological distress, respiratory distress, cardio-circulatory distress) were included. 


\subsection{Management and Diagnosis of Life-Threatening Pediatric Emergencies}

The emergency unit is headed by 1 pediatrician under whom there are 2 general practitioners, 3 nurses and 7 nursing aids. They work on a permanent basis. Doctors from other units and teams of nurses from the department intervene during duty and on call. The nursing round precedes the medical round, and takes place once a day. The medical doctors on call and the team of nurses take turns from 3 p.m. to 8 a.m. except on public holidays according to a pre-established schedule, this is done under the supervision of a care coordinator and a pediatrician. After identification and vital sign measurements, all patients received at the emergency unit benefit from a rapid assessment of the clinical condition for an adequate referral. All admissions are recorded in a register.

In case of vital distress, "a green voucher" is issued by the doctor. This is receipt issued for internal care that permits deferred payment.

This allows immediate and unconditional access to laboratory and imaging tests, medications and blood transfusion if necessary. It is issued by a doctor after evaluation of the type of emergency and must first be validated at the cash desk to be accepted in the various services requested. Full recovery of care related costs occurs before the child is discharged from the hospital. In the event of proven indigence, the social services of the LHD is contacted.

As soon as the patient is admitted at the emergency unit, conditioning and first aid care is been provided thanks to the emergency kits available and adapted to common pathologies. These kits contain essential drugs and tools for the diagnosis and emergency management of the most frequently encountered pathologies. The emergency kits available concerned pathologies such as: severe anemia, severe dehydration, shock, convulsions, meningitis, malaria, neonatal infection and asphyxia. For any child admitted with a fever $>38.5^{\circ} \mathrm{C}$, the rapid diagnostic test for malaria, HIV, blood sugar and urine test strips. As soon as the patient is clinically stable, he is transferred to a unit suitable for his care.

After doing a pre-test with 10 parents/guardians, the questionnaire was validated. On admission to the pediatric emergency room, an assessment of the child to determine the criticality of the emergency and the parents or legal guardians of all children in life-threatening emergencies were submitted to the questionnaire after giving their consent. Data was collected for statistical analysis.

\subsection{Variables Studied}

- The socio-demographic characteristics of the parents: age, marital status, level of education, and profession.

- The socio-demographic characteristics of the patients: age, sex, place of residence and provenance.

- The clinical characteristics of the patient: reason for consultation, medical history, physical signs, type of vital emergency, etiological diagnosis, emergency measures, type and time of treatment. 
- Evolutionary characteristics: number of hours spent in the emergency room, length of hospital stay in days, hospital mortality rate.

\subsection{Operational Terms}

Vital emergency: A vital emergency is characterized by the appearance of a distress of a vital function which can lead at any time to cardiac arrest. This emergency therefore calls into question the patient's vital prognosis, that is to say, it designates the patient's risk of death or the chances of survival. Neurological emergency: it is a condition causing a more or less complete loss of consciousness of life's relationship functions and a marked vegetative participation of life. Respiratory emergency or acute respiratory failure is a syndrome defined as functional lung impairment resulting in hypoxemia, hypercapnia or both and is related to the failure of one or more components of the respiratory system (airways, pulmonary parenchyma, pleura, vessels, respiratory muscles and respiratory control).

Cardio-circulatory emergency: this could be a collapse, hemodynamic shock or cardiopulmonary arrest.

- Collapse is a transient hemodynamic failure, the consequence of an acute and transient imbalance between vascular capacity and blood volume.

- Hemodynamic shock is acute and lasting circulatory insufficiency which impairs tissue perfusion and leads to cellular hypoxia.

- Cardio-circulatory arrest is a sudden interruption of blood circulation in the body, accompanied by ventilatory arrest, loss of consciousness and resulting in the death of the patient. The green voucher: internal care voucher with recovery of the costs of deferred care (treatment of patients without delay with payment of the costs of care when the patient is discharged).

\subsection{Statistical Analysis}

The data were entered and coded in excel 2010 software and analyzed with the SPSS statistics version 23 software. The qualitative variables were expressed in numbers and percentages and the quantitative variables in means and standard deviations.

\section{Ethical Considerations}

We obtained research authorization No. 0647 of March 01, 2017 from Laquintinie Hospital Douala and ethical clearance from the ethics committee of the University of Douala No. 881/16/2017 /T. Data was collected anonymously and was used only for research purposes

\section{Results}

Of the 318 patients who were admitted at the pediatric emergency department of the LHD during the study period, 135 patients presented with a life-threatening emergency, giving us hospital prevalence of life-threatening emergencies of $42.4 \%$. 
More than 4/5 of emergencies were neurological, 35.6\% respiratory emergencies and $18.5 \%$ cardio-circulatory emergencies (Figure 1 ).

\subsection{Socio Demographic Characteristics}

Infants accounted for $43.7 \%$ (59/135) and children aged 5 years and over, $19.3 \%$ $(26 / 135)$ of patients. The average age of the children was 3.8 years with extremes ranging from $82 \pm 47$ months. Boys represented $60.7 \%(82 / 135)$ of patients and the sex ratio was 1.54 (Table 1 ).

Patients with a life threatening emergency resided in the Cité des Palmiers health district in $20.0 \%$ (27/135) of cases, in the Nylon health district in $16.3 \%$ $(22 / 135)$ of cases and in the Déido health district, where HDL is located, in only $14.1 \%(12 / 135)$ of cases. Most parents or guardians of patients had secondary education; $50.0 \%(50 / 100)$ for fathers and $60.0 \%$ (63/105) for mothers. Selfemployed fathers constituted $60.0 \%(60 / 100)$ of the sample and $46.6 \%(43 / 105)$ of mothers were unemployed (Figure 2).

Table 1. Distribution of patients according to age and sex.

\begin{tabular}{ccc}
\hline Variables & $\begin{array}{c}\text { Number } \\
\mathbf{n}\end{array}$ & $\begin{array}{c}\text { Percentage } \\
\%\end{array}$ \\
\hline $\begin{array}{c}\text { Age ranges, years } \\
<2 \text { years }\end{array}$ & 59 & 43.7 \\
{$[2-5$ years $]$} & 50 & 37.0 \\
$\geq 5$ years & 26 & 19.3 \\
Sex & & \\
Girls & 53 & 39.3 \\
Boys & 82 & 60.7
\end{tabular}

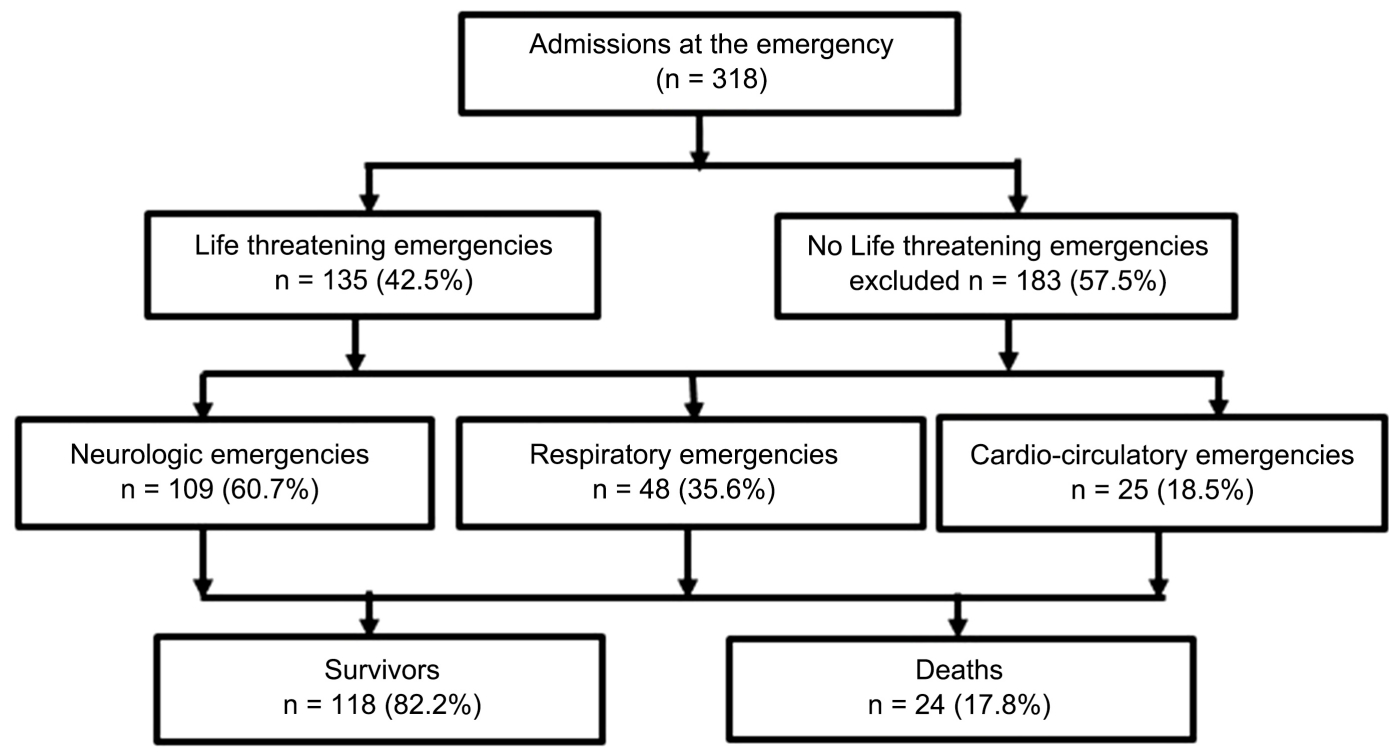

Figure 1. Global presentation of the study results. 


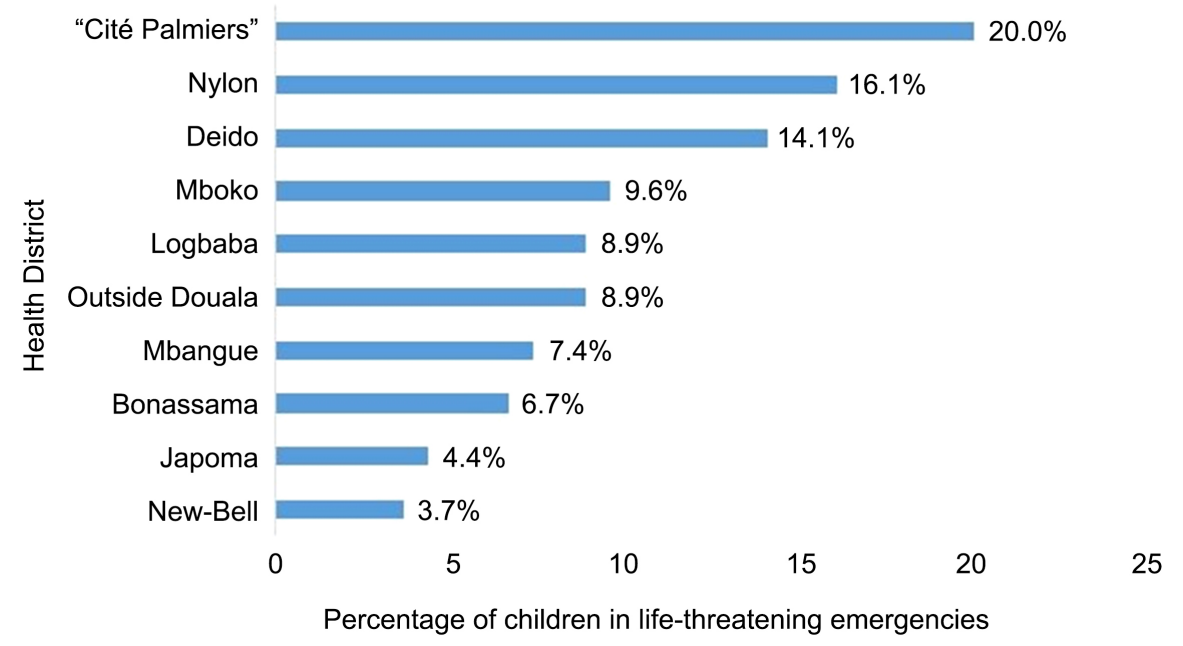

Figure 2. Distribution of children in life-threatening emergencies according to place of residence.

\subsection{Clinical Characteristics}

\subsubsection{Medical History and Reception Conditions on Admission of Life-Threatening Emergencies Patients}

More than $3 / 4$ of patients $(82.9 \%, 112 / 135)$ admitted for life-threatening emergencies came from another hospital facility and $17.0 \%$ (23/135) came from home. The majority of patients $(63.0 \%, 85 / 100)$ admitted for life-threatening pediatric emergencies reported having no previous relevant medical history. History of infectious disease accounted for $22 \%$ (30/135), neurological disease for $11.0 \%(15 / 135)$ and respiratory disease for $10.0 \%$ (13/135) of cases. The mean time to consultation after disease onset was 6.0 days (1-60 days) and the median was 4 days (Table 2).

Of the patients included, $66.0 \%(89 / 100)$ of children in a critical emergency were admitted to the emergency room between 3 p.m.-7:59 a.m. and 71 (52.6\%) received an internal care voucher with recovery of deferred cost or "green voucher". The majority of patients $(75.6 \%$; 102/135) were managed within 30 minutes of admission.

\subsubsection{Physical Signs on Examination on Admission of Life-Saving Emergencies Patients}

More than a third of the patients $(34.8 \%, 46 / 135)$ had consulted for seizures, dyspnea represented $(25.2 \%, 34 / 135)$ and fever $(21.5 \%, 29 / 100)$. The vast majority of patients in life-saving emergencies presented to the emergency unit with a deterioration in general condition resulting in asthenia (77.0\%, 103/135), anorexia $(64.0 \%, 86 / 135)$ and almost half of the patients mucocutaneous pallor (47.0\%, 63/135).

On physical examination, coldness of the extremities 28 (20.7\%) and dryness of the mucous membranes $12(8.9 \%)$ were the main cardiovascular signs found on admission of patients. Dyspnea $67(49.6 \%)$ accounted for nearly half of the respiratory signs found, rales and flapping of the wings of the nose were found in 
the respective proportions $(45.2 \% ; 61 / 135)$ and $(43.0 \%$; 58/135) while cyanosis was little present $(1.5 \% ; 2 / 135)$. More than half of the critically ill children presented with seizures $52.6 \%$ and $47.4 \%$ were admitted in a comatose state (Table 3 ).

\subsubsection{Type of Life-Threatening Emergencies and Management at Admission}

Neurological pediatric life-threatening emergencies $(80.7 \%, 109 / 135)$ dominated the picture with convulsions $(47.4 \%, 64 / 109)$ and comas $(33.3 \%, 45 / 109)$, followed by respiratory emergencies $(35.6 \%, 48 / 135)$ and cardio-circulatory emergencies $(18.5 \%, 25 / 135)$, mainly consisting of hypovolemic shock in $15.6 \%$ (21/135) of cases. The average length of stay in the emergency room was 2.6 days (min-max: 1 - 44 days). The death rate from life-saving emergencies was $17.8 \%$ (24/135). The number of deaths from life-threatening emergencies accounted for more than half $(61.5 \%)$ of the 39 deaths recorded in the pediatric emergency department (Table 4).

Table 2. Medical history of life-threatening emergencies patients.

\begin{tabular}{|c|c|c|}
\hline Variables & Number, $\mathrm{n}$ & Percentage, $\%$ \\
\hline \multicolumn{3}{|c|}{ Medical history, $\mathrm{n}=135$} \\
\hline Unknown medical history & 85 & 63.0 \\
\hline Infectious diseases & 30 & 22.0 \\
\hline Neurological diseases & 15 & 11.0 \\
\hline Respiratory diseases & 13 & 10.0 \\
\hline Cardiovascular diseases & 2 & 1.5 \\
\hline Past surgical history & 3 & 2.2 \\
\hline Drug allergies & 1 & 0.7 \\
\hline Blood transfusion & 5 & 3.7 \\
\hline \multicolumn{3}{|c|}{ Delay of consultation, $\mathrm{n}=135$ (Mean 6,0 days (min-max: $1-60$ days; SD 8.63) } \\
\hline$\leq 1$ day & 32 & 23.7 \\
\hline 1 - 2 days & 11 & 8.1 \\
\hline $3-7$ days & 69 & 51.1 \\
\hline$>7$ days & 23 & 17.0 \\
\hline \multicolumn{3}{|c|}{ Taking previous treatment before admission } \\
\hline No treatment & 17 & 13.0 \\
\hline Medical treatment & 88 & 65.0 \\
\hline Medical treatment + phytotherapy & 26 & 19.0 \\
\hline Phytotherapy & 4 & 3.0 \\
\hline
\end{tabular}




\subsection{Limitations of Study}

The first study carried out on children in life-threatening emergencies, it has enabled us to obtain interesting results for the improvement of medical care. However, it was made that in a single hospital center, this would suggest a caution in the generalization for the interpretation of the results compared to other hospitals although the Laquintinie hospital in Douala is a reference hospital in the city.

Table 3. Physical signs on admission of life-threatening emergencies patients.

Physical signs on admission

Cardiovascular signs on admission

Cold extremities
Mucosal dryness
Cardiac murmurs
Lower limb edema
Mottled skin appearance
Cardiac arrest

Respiratory signs on admission

$$
\begin{aligned}
& \text { Dyspnea } \\
& \text { Crackles }
\end{aligned}
$$

Flapping of the wings of the nose

Intercostal retractions

Noisy breathing

Paradoxal breathing

Cyanosis

Neurological signs on admission

Convulsions

Coma

Kernig sign

Nuchal rigidity

Hypotonia

Bulging or depressed fontanel

Brudzinski sign

Paralysis

Babinski sign
28

12

5

4

3

2

67

61

58

52

30

26

2 
Table 4. Type of life-threatening emergencies and management at admission.

\begin{tabular}{|c|c|c|}
\hline Variables & Number, $\mathrm{n}$ & Percentage \% \\
\hline \multicolumn{3}{|l|}{ Neurological distress } \\
\hline Convulsion & 64 & 47.4 \\
\hline Coma stage 1 & 19 & 14.1 \\
\hline Coma stage 2 & 11 & 9.6 \\
\hline Coma stage 3 & 12 & 8.1 \\
\hline Coma stage 4 & 2 & 1.5 \\
\hline Respiratory distress & 48 & 35.5 \\
\hline \multicolumn{3}{|l|}{ Cardiovascular distress } \\
\hline Hypovolemic shock & 21 & 15.6 \\
\hline Septic chock & 1 & 0.7 \\
\hline Cardio-respiratory shock & 3 & 2.0 \\
\hline \multicolumn{3}{|l|}{ Delay in management } \\
\hline$<30 \min$ & 102 & 75.6 \\
\hline $30-60 \mathrm{~min}$ & 25 & 18.5 \\
\hline$>60 \mathrm{~min}$ & 3 & 2.0 \\
\hline \multicolumn{3}{|c|}{ Length of stay at the emergency } \\
\hline$\leq 1$ day & 29 & 21.0 \\
\hline [1 - 2] days & 61 & 45.0 \\
\hline [2 - 3] days & 17 & 13.0 \\
\hline$\geq 3$ days & 28 & 21.0 \\
\hline
\end{tabular}

\section{Discussion}

Our work focused on the epidemiological profile of pediatric life-threatening emergencies (PLTE) and the short-term evolution of patients admitted to the pediatric department at Laquintinie Hospital in Douala. The hospital prevalence of pediatric life-threatening emergencies was $42.4 \%$. Nzame et al., in Gabon (2020), Guedenon et al. in Togo (2017) and Kingwengwe et al. in DRC (2019), had reported a prevalence of PLTE which varied from $18.3 \%$ to $21.4 \%$ in their respective previous studies [7] [8] [9].

The high trend in our series could be explained by the geographical location of this referral hospital which has a technical platform to receive patients with serious pathologies on the one hand and on the other hand, access to care is facilitated through the issuance of internal vouchers (green vouchers) with deferred recovery of care costs. In our study, $60.0 \%$ of fathers were informal sector workers and $46.7 \%$ of mothers were unemployed. A similar trend of precarious employment or parental unemployment reflecting a low socio-economic level was also observed by Fatou Ly in Senegal (2016) [10]. More than 3 out of 5 children 
in our study were male and the sex ratio was 1.54 . This result was similar to those found by Nzame et al. in Gabon, Ly Fatou in Senegal in 2016 and Asse et al., in Ivory Coast (2012). This was unlike results by Enyuma et al. in Nigeria (2014) which had found a female predominance [8] [10] [11] [12]. The mean age of the patients was 3.80 years, and children under 5 years of age accounted for $80.7 \%$ of patients. This distribution was lower than that found by Guedenon in Togo and higher than that reported in Gabon, Senegal and Morocco, whose proportions varied from $68.8 \%$ to $72.7 \%$ [8] [9] [10] [13]. The vulnerability to infections, the rapid evolution and the early complications of childhood illnesses common in this age group could explain this situation.

More than 3/4 of patients admitted for life-threatening emergencies came from a peripheral hospital structure and only $17.0 \%$ came from their homes. These results were similar to those reported by Roukia et al. in Morocco (2019), where $61.2 \%$ came from other peripheral health facilities unlike previous studies carried out in Senegal, in Benin and in Cameroon where the majority of patients came from their homes [10] [11] [14] [15]. The reasons given for their choice and the therapeutic course are the perception of the mild disease by the parents at the onset of the symptoms while the persistence and severity of the disease were the main reasons why they ended up going for consultation in health facilities according to Ndukwu et al. in Nigeria (2015) [16]. Before arriving at the pediatric emergency department at HLD, $87.4 \%$ of patients had received previous treatment. These results were superior to those reported by Penda et al. in Cameroon (2017), and Enyuma et al. where $74.1 \%$ and $50.7 \%$ had received selfmedication before admission to the pediatric emergency unit, respectively [12] [15]. The mean time to consultation after the onset of the disease was 6.0 days and more than $3 / 5$ of the patients with PLTE were admitted between 3 p.m. 7:59 a.m. This delay was greater than that found by Penda et al., However it was multiplied by three in the series reported by Ndukwu et al. [15] [16]. The long therapeutic course of sick children leads to a delay in consultation due to the underestimation of the severity of the disease by the parents, and ultimately lead to the delay in the diagnosis of emergency situations or complications in downstream health structures. These situations would be detrimental to the survival of the child. Regarding admission times, our results were consistent with those of Enyuma et al. and Fatou Ly et al. where life-threatening emergencies were mostly received during on-call hours [10] [12]. The most frequent reasons for consultation were seizures, dyspnea and fever. These data were comparable to that found by previous studies [6] [8] [12] [13] [17]. More than 3 in 4 patients with PLTE were treated within 30 minutes of admission. This trend is higher than that reported by other authors [8] [10]. This early management could be explained by the measures put in place in the service to overcome the delay in management with the use of an internal voucher (green voucher) with deferred care cost recovery and local emergency kits. Neurological pediatric life-threatening emergencies dominated the picture with convulsions and comas, followed 
by respiratory and cardio-circulatory emergencies. These results were comparable to those found by El Gajoui et al. in Morocco (2017) but in different proportions because the respiratory emergencies accounted for nearly half of the cases (45.3\%) followed by neurological (25.1\%), and cardio circulatory (20.7\%) emergencies [19].

The spectacular clinical presentation of the convulsions and respiratory distress could explain the more numerous urgent consultations in our series. The vulnerability of children to these pathologies is thought to be one of the causes of the early development of this type of complications. Severe malaria was the primary etiology of PLTE, as similarly reported by several previous studies [5] [7] [11] [12] [15]-[20]. These results confirm that severe malaria remains the leading cause of morbidity, particularly in children aged 0 - 5 years. In general, infectious pathologies dominate the table of etiologies of vital emergencies in our sample. Pulmonary infectious pathologies took second place and can be compared to the results of Ejlaidi et al. and Enyuma et al. in Nigeria, where the frequencies of respiratory infections and malaria were comparable (53.7\% and 52.4\% respectively) [12] [13]. The average length of emergency hospital stay was 2.7 days (min-max: 1 - 44 days), Enyuma et al. reported a similar trend in their study in Nigeria [12]. In our series, the pediatric emergency unit received patients until their stabilization. The average length of stay in the pediatric emergency room was 2.7 days (min-max: 1 - 44 days), Enyuma et al. reported a similar trend in their study in Nigeria [12]. In our series, the intensive care unit received patients until their stabilization. The death rate from life-saving emergencies was $17.8 \%$. The number of deaths from life-threatening emergencies accounted for more than half (61.5\%) of the 39 deaths recorded in the pediatric emergency department. A similar trend was found by Kingwengwe in DRC and Guedenon in Togo [7] [9], lower than that found by Edulu et al. in Nigeria but higher in the series of El Gajoui in Morocco [18] [19]. In all these series, mortality more particularly concerned children under 5 years old. These results highlight their great vulnerability to infections at this age.

\section{Conclusion}

Almost half of the children admitted to pediatric emergencies had a life-threatening emergency. The profile of a life-threatening pediatric emergency is that of a boy, less than 5 years old, coming from a peripheral health facility after having received previous treatment. Infectious pathologies dominated the etiological profile. The very high mortality of life-threatening emergencies could be avoided by setting up staff capacity building, the technical platform and innovative strategies to facilitate the care of patients at a low socio-economic level in our context of limited resources.

\section{Acknowledgements}

We thank the staff of the pediatric emergency department at Laquintinie Hos- 
pital for their support in this work as well as all the people who contributed to the success of the work

\section{Authors' Contribution}

CIP, DKKM and MKL contributed in the conception of this work. CIP, MKL, EBB contributed for data collection and analysis. CIP, EMLM and SBF conceived and wrote the draft manuscript. CIP, SBF, EEC, EMLM and DKKM contributed in proofreading the manuscript.

\section{Conflicts of Interest}

The authors declare no conflicts of interest regarding the publication of this paper.

\section{References}

[1] Sharrow, D., Hug, L., Liu, Y. and You, D.Z. (2020) Levels \& Trends in Child Mortality Report 2020. Estimates Developed by the UN Inter-Agency Group for Child Mortality Estimation. United Nations Inter-Agency Group for Child Mortality Estimation. (UNIGME).

[2] Institut National de la Statistique (INS) and ICF (2020) Enquête Démographique et de Santé du Cameroun 2018. Yaoundé, Cameroun et Rockville, Maryland, USA.

[3] Tang, D., Tou, J., Wang, J., Chen, Q., Wang, W., Huang, J., et al. (2020) Prevention and Control Strategies for Emergency, Limited-Term, and Elective Operations in Pediatric Surgery during the Epidemic Period of COVID-19. World Journal of Pediatric Surgery, 3, e000122. https://doi.org/10.1136/wjps-2020-000122

[4] Valentine, J. (2016) $1 \mathrm{mg}$ d'expérience Toutes les 3 Minutes 150mg de qualité. https://www.infirmiers.com/pdf/tfe-valentine-jacquier.pdf

[5] Azoumah, D.K. (2010) Les urgences médicales pédiatriques au Chu-campus de Lomé: Aspects épidémiologiques. Journal de la Recherche Scientifique de P Université de Lomé, 12. https://www.ajol.info/index.php/jrsul/article/view/68040 https://doi.org/10.4314/jrsul.v12i2.68040

[6] Coulibaly, B. (2006) Les urgences medicales pediatriques dans le service de pediatrie du c.h.u-gabriel toure. http://www.keneya.net/fmpos/theses/2006/med/pdf/06M265.pdf

[7] Kingwengwe, A.A., Ndjadi, A.K., Lukusa, P.M., Ilunga, P.M., Ibeki, E.K., Kyanga, P.A., et al. (2019) Epidemiology of Pediatric Medical Emergencies at the Kindu Reference General Hospital (HGRK): State of Affairs and Perspectives. Open Access Library Journal, 6, 1-9. https://doi.org/10.4236/oalib.1105715

[8] Nzame, Y., Ntsame, S., Ndoutoume, R., Gahouma, D. and Koko, J. (2020) Epidémiologie des Urgences Pédiatriques de Nuit au Centre Hospitalier Universitaire de Libreville. Health Sciences and Disease, 21, 88-91.

[9] Guedenon, K.M., Adani Ife, A.A., Fiawoo, M., Akolly Bagny, D.A.E., Dossou, F.C., Gnassingbe, K., et al. (2017) Les urgences médicales dans les unités de soins continus pédiatriques au CHU Sylvanus Olympio de Lome. Journal de la Recherche Scientifique de l'Université de Lomé, 19.

[10] Ly, F., Keita, Y., Niang, B., Camara, B., Ly, B., Dème, L., et al. (2016) Profil épidémiologique des consultants admis aux urgences médicales pédiatriques du Centre Hospitalier National de Pikine. RAMReS Sciences de la Santé, 4, 4-10. 
[11] Assè, K.V., Plo, K.J., Yao, K.C., Konaté, I. and Yenan, J.P. (2012) Profil épidémiologique, diagnostique, thérapeutique et évolutif des malades référés aux urgences pédiatriques du CHU de Bouake (Cote d'Ivoire). Rev Afr Anesth Méd Urg, 17, 81-87.

[12] Enyuma, C.O., Anah, M.U., Pousson, A., Olorunfemi, G., Ibisomi, L., Abang, B.E., et al. (2019) Patterns of Paediatric Emergency Admissions and Predictors of Prolonged Hospital Stay at the Children Emergency Room, University of Calabar Teaching Hospital, Calabar, Nigeria. African Health Sciences, 19, 1910-1923. https://doi.org/10.4314/ahs.v19i2.14

[13] Ejlaidi, A. and Bouskraoui, M. (2010) Enquête multicentrique sur les urgences pédiatriques.

http://wd.fmpm.uca.ma/biblio/theses/annee-htm/art/2010/article15-10.pdf

[14] Roukia, S. (2019) Consultations aux urgences médicales pédiatriques : qui, pourquoi et comment? À propos de 1000 consultants.

http://ao.um5.ac.ma/xmlui/handle/123456789/17133

[15] Penda, C.I., Moukoko, E.C.E., Youmba, J.F.N. and Mpondo, E.M. (2018) Characterization of Pharmaceutical Medication without a Medical Prescription in Children before Hospitalization in a Resource-Limited Setting, Cameroon. Pan African Medical Journal, 30, Article ID: 302. https://doi.org/10.11604/pamj.2018.30.302.16321

[16] Ndukwu, C. and Onah, S. (2015) Pattern and Outcome of Postneonatal Pediatric Emergencies in Nnamdi Azikiwe University Teaching Hospital, Nnewi, South East Nigeria. Nigerian Journal of Clinical Practice, 18, 348-353. https://doi.org/10.4103/1119-3077.153246

[17] Akodjènou, J., Zounmènou, E., Lokossou, T.C., Assouto, P., Aguémon, A.R. and Chobli, M. (2013) Les urgences pédiatriques du service de pédiatrie de l'hôpital de zone d'Abomey-Calavi/Sô-Ava (BENIN). Société de l Anesthésie Réanimation d'Afrique Francophone, 18.

[18] Edelu, B.O., Eze, J.N., Oguonu, T. and Ndu, I.K. (2014) Morbidity and Mortality Pattern in the Children Emergency Unit of the University of Nigeria Teaching Hospital Enugu. Orient Journal of Medicine, 26, 48-54.

[19] El Gajoui, B., El Mahdi Boubkraoui, M., Mekaoui, N., Karboubi, L. and Dakhama, B.S.B. (2017) Acute Life-Threatening Illnesses Epidemiology at a Pediatric University Hospital's Medical Emergency Department in Morocco. International Journal of Current Research, 9, 57780-57783.

[20] Ndu, I.K., Uleanya, N.D., Nwokoye, I.C., Edelu, B.O., Asinobi, I.N., Ekwochi, U., et al. (2016) Pattern of Morbidity and Mortality at the Children Emergency Unit of Enugu State Teaching Hospital, Park lane, Enugu. Journal of Experimental Research, 4. 